\title{
EL NUEVO DICCIONARIO NIETZSCHE
}

- Nietzsche-Wörterbuch, editado por el Nietzsche Research Group (Nijmegen).

- bajo la dirección de Tongeren, Paul van; Schank, Gerd y Siemens, Herman.

- Band 1: Abbreviatur-einfach.

- Berlin/New York: Walter de Gruyter, 2005.

- XXXII+763 pp. ISBN 3-11-017186-4.

Acaba de publicarse el primer volumen, de los cuatro o cinco proyectados, del Diccionario-Nietzsche, una obra de gran interés y envergadura llevada a cabo desde 1998 por el Nietzsche Research Group, de la Facultad de filosofía de la Universidad de Nijmegen, Holanda, que espera terminar la edición hacia 2010. En anteriores números de Estudios Nietzsche (n ${ }^{\circ} 4$, pp. 85-104; $\mathrm{n}^{\circ} 3$, pp. 207-214) hemos venido hablando de la gestación de dicho proyecto y de sus pretensiones y objetivos. En este primer volumen se incluyen 67 conceptos del vocabulario de Nietzsche de los 500 que abarcará el diccionario.

Con ello comienza a hacerse realidad uno de los instrumentos más necesarios para comprender el pensamiento de Nietzsche, es decir, contar con un diccionario sobre Nietzsche, en el que se pudiese tener su 'vocabulario principalmente filosófico' explicado en términos 'histórico-sistemáticos'. Sin duda, con este diccionario podremos precisar mejor el sentido de sus textos, al poder contar con una descripción pertinente de los términos y su plurivocidad a tenor de los distintos contextos. Hasta ahora, frente a términos complejos, teníamos que recurrir a un análisis pormenorizado de los diversos lugares paralelos con esfuerzo complementario y no siempre con un éxito garantizado. Con el nuevo diccionario podemos comprender cada uno de los términos en su uso, en su formación, los sinónimos y palabras afines.

Nietzsche solía decir que él había enriquecido la lengua alemana con nuevas palabras y que había dado nuevos significados a palabras ya existentes. Incluso, si nosotros descuidamos estas explicaciones, está claro que para Nietzsche la formulación de su pensamiento en un lenguaje es una cuestión que atañe a su pensamiento más que a otros filósofos. Él sabe y hace uso de las seducciones y trampas del lenguaje, al que concibe como una multitud de metáforas que son en principio mudables. No solamente cambia el significado de ciertas palabras, a medida que evoluciona su pensamiento, sino que también trabaja conscientemente, más que la mayoría de los filósofos, con la posibilidad de adscribir 
diferentes significados a las mismas palabras a través de contextualizaciones diferentes y desplegando varias ópticas. El perspectivismo no es una simple teoría en la obra de Nietzsche, sino sobre todo una práctica. Una buena parte de su vocabulario tiene al menos un doble significado, en cuanto que es usado positivamente en un sentido afirmativo y negativamente en un sentido crítico. Pero además, todos saben que frecuentemente y de una manera intencionada hace un uso plurivocista de las palabras, buscando el sentido primigenio de las mismas, su sentido figurado y metafórico, etc. Todos estos procedimientos operan dentro del marco de la meta filosófica de Nietzsche: conseguir una transvaloración de los valores existentes, dentro de la cual el lenguaje juega un papel crucial, pues una de las obsesiones de Nietzsche fue siempre liberarse de las redes del lenguaje que aprisionaban inexorablemente al filósofo hasta asfixiarle.

Los autores del Diccionario también han tenido en cuenta las perspectivas desde las que habla Nietzsche en sus textos. En este sentido los puntos de vista cambian constantemente y por eso se puede decir que en los textos de Nietzsche las variedades semánticas se enfrentan. Así, por ejemplo, según los autores, se puede hablar de un punto de vista de los griegos, es decir, un discurso y un uso del lenguaje desde la óptica de los griegos, para lo que hay que mencionar aquí ante todo a los presocráticos con Heráclito, cuando se trata de hablar de 'opuestos' y de 'devenir'. Además de eso también juega continuamente un papel importante la óptica de la moral y de la religión cristiana. Hablar desde la óptica de la filosofía de Schopenhauer es algo que se circunscribe, por el contrario, al Nietzsche joven. Esto explica, por ejemplo, que a veces los puntos de vistas se alternen, como es el caso de la metáfora de la serpiente en el Zaratustra, donde aparece, por un lado, como 'la compañera preferida' de Zaratustra (junto con el león) y, por otro lado, es también repugnante, como la 'serpiente negra' del nihilismo. Una superposición de ópticas está presente a menudo en el uso de las 'comillas'. Además, Nietzsche, como filólogo, era un buen conocedor de las cuestiones relativas al lenguaje, y esto ciertamente le permitió construir una base sólida para su discurso, pero también era un artista del lenguaje, un creador del lenguaje. Y como filósofo estaba convencido ante todo del influjo del lenguaje en el pensamiento y viceversa. Sabía, por otro lado, entrever que la realidad polisémica del lenguaje podía ser un instrumento adecuado para romper el poder de toda dogmatización, con lo cual el lenguaje es, sin embargo, con frecuencia un instrumento resistente, porque está encadenado a aquello que lo intenta romper. La metáfora de 'filosofar con el martillo' también tiene su aplicación en este contexto. Nietzsche trata de 'romper' las palabras, desestabilizarlas en su inquebrantable sentido conceptual y dotarlas de una flexibilidad tal que se pueda vislumbrar la fuerza metafórica e imaginativa que contienen.

Otra de las cuestiones a tener en cuenta es que la crítica radical del lenguaje en la filosofía de Nietzsche está estrechamente relacionada con su teoría de la transvaloración de los valores. En este sentido, para evitar los malentendidos 
metafísicos, lógicos o dialécticos de su proyecto de transvaloración, Nietzsche transforma a veces el sentido de los conceptos, de tal manera que expresiones con valor positivo cobran un valor negativo, o bien expresiones con valor negativo cobran un valor positivo. Estas sustituciones de valores son producidas, por lo general, mediante una confrontación crítica con expresiones específicas. El presente Diccionario puede arrojar mucha luz con su investigación de los significados, variaciones y cambios de significado de las palabras específicas.

Debido al continuo desarrollo del lenguaje, los lectores no pueden hoy simplemente dar por supuesto que su comprensión de las palabras y del lenguaje está de acuerdo con las del autor a quien ellos están leyendo. A parte del hecho de que Nietzsche a veces se inspira específicamente sobre un significado antiguo de las palabras que él está usando, la lengua alemana del diecinueve no es la misma que el alemán actual. Como resultado de la mutación lingüística y de las correcciones ortográficas pertinentes a lo largo del siglo XX, un considerable número de palabras tienen un significado diferente (primario), u otras connotaciones, del que tenían para Nietzsche y sus contemporáneos. Por eso hay que ser prudentes a la hora de traducir algunos conceptos, pues muchas veces se distorsiona lo que realmente quería decir Nietzsche, que no es lo mismo que los alemanes de hoy entienden cuando utilizan la misma palabra. Además, la manipulación a la que ha sido sometida la obra de Nietzsche ha provocado que se atribuya un sentido interesado a determinados términos, que en su origen significaban otra cosa. Términos como 'voluntad de poder', 'esclavitud', 'bestia rubia', 'raza', se interpretaron sesgadamente a favor de intereses políticos determinados. Por eso los autores del Diccionario creen que éste servirá, entre otras cosas, para que los lectores puedan enfrentarse con un instrumento adecuado a lecturas engañosas y cotejar el significado específico de las palabras según el contexto dado en las obras de Nietzsche. Pero sobre todo, los traductores podrán a partir de ahora contar con una ayuda inestimable para fijar coherentemente el significado de muchas palabras que hasta ahora ofrecían una verdadera resistencia a una traducción adecuada.

El equipo que ha llevado a cabo esta obra ha hecho la selección de lemas teniendo en cuenta una serie de criterios. A la hora de valorar el alcance de este Diccionario no hay que perderlos de vista: en primer lugar, se ha atendido a la importancia de la palabra (o grupos de palabras) en el pensamiento de Nietzsche; conjeturas respecto a nuevos significados que Nietzsche dio a palabras específicas en contraste con el trasfondo de su propia época o con la historia anterior de la palabra; el peso dado a una palabra en el curso de la interpretación de Nietzsche; distorsiones posibles y ofuscaciones de una palabra, o bien a través de la 'vulgarización' y 'esloganización' de la misma, o bien a través de la interpretación 'interesada' de su filosofía en los años de 1933-1945; o a través de factores adicionales que podían impedir una compresión más precisa del texto para los lectores actuales. 
Los autores del Diccionario tomaron como punto de partida el cd-rom de la edición de Colli y Montinari, Kritische Studienausgabe y Kritische Gesamtausgabe der Werke, disponible desde 1995. Y también la edición de ambos autores de las cartas, la Kritische Studienausgabe sämtlicher Briefe y la Kritische Gesamtausgabe Briefe. El número de palabras de las cartas fue seleccionado e integrado sobre la base de la lectura de las mismas. De esta forma, a la hora de describir una palabra utilizaron las instancias de su uso principalmente en KSA. Pero además, el comentario de cada uno de los términos tiene otros soportes: los autores hacen constancia de la utilización de los diccionarios más importantes de la lengua alemana, un significativo número de obras filosóficas de consulta (diccionarios, enciclopedias, etc.), la literatura de investigación en filosofía y lingüística, las monografías relevantes para la terminología dada, comentarios de la obra de Nietzsche, los índices de citas de la revista Nietzsche-Studien, etc. Partiendo de todo este rico material los investigadores elaboraron un esquema para cada una de las entradas en las que figuran los siguientes datos:

En primer lugar, para cada lema, se informa de las veces en que aparece, y cuando procede se incluyen las variantes ortográficas y sinónimos.

En segundo lugar, se establece un sumario en relación a los resultados más significativos del semema.

En tercer lugar, se establecen los diferentes significados, connotaciones y variantes dependiendo de los contextos. Los significados son establecidos a través de una cuidadosa y minuciosa lectura de los lugares en donde aparece la palabra.

En cuarto lugar, se ofrece un boceto de la historia de la palabra relevante y del concepto en términos de teoría lingüística y literaria, así como el modo en que Nietzsche lo usa. Es importante en este contexto la relación en el uso del lenguaje entre Nietzsche y sus contemporáneos.

En quinto lugar, estudia el contexto filosófico e histórico en sentido amplio (biográfico, histórico artístico y político), de tal manera que pueda contribuir a la descripción de la historia conceptual del lema. Con la ayuda de esta información los significados diferentes y los contextos pueden ser referidos a un marco interpretativo. En esta sección se alude a la investigación sobre Nietzsche, especialmente a las publicaciones de Nietzsche-Studien y a la colección Monographien und Texte zur Nietzsche-Forschung.

La intención de los editores es que también pueda publicarse una versión completa en formato electrónico de cd-rom, o bien integrar el diccionario con el cd-rom de las KSA (en una versión mejorada), y si es posible, con una versión electrónica de la Bibliografía Completa de la literatura de investigación de Nietzsche, publicada ya en el 2002 (J.B. Metzler Verlag). Una significativa ventaja de una publicación electrónica como ésta sería que las correcciones y enmiendas podrían hacerse más fácilmente.

Luis Enrique de Santiago Guervós Universidad de Málaga 